\title{
Raised intracranial pressure and cerebral blood flow
}

\section{Effects of episodic intracranial pressure waves in primates}

\author{
I. H. JOHNSTON, J. O. ROWAN, D. M. PARK, AND M. J. RENNIE
}

From the Medical Research Council Cerebral Circulation Research Group and the University Department of Neurology at the Institute of Neurological Sciences, and the Wellcome Surgical Research Institute, Glasgow

SYNOPSIS The effects of episodic waves of intracranial pressure on cerebral blood flow were studied in primates. Six pressure waves each of 20 minutes' duration and ranging from 50 to 100 $\mathrm{mmHg}$ in magnitude were induced in baboons, at intervals of 30 minutes, in an attempt to simulate clinical plateau waves. With pressure waves up to $75 \mathrm{mmHg}$, cerebral blood flow remained at control levels despite falling cerebral perfusion pressures. Between the initial pressure waves a marked hyperaemia developed, with cerebral blood flow increasing by as much as $100 \%$, and this appeared to be the means whereby adequate flow was maintained during pressure waves. Later pressure waves, up to $100 \mathrm{mmHg}$, eventually reduced blood flow below control levels, although moderately high flows were maintained during periods of very low perfusion pressure. Brain metabolism was affected by the episodic pressure waves, although no consistent change was seen.

In studies of the inter-relationship between intracranial pressure and cerebral blood flow a variety of methods of raising intracranial pressure have been used and the results have been, in quantitative terms, quite variable (Kety et al., 1948; Greenfield and Tindall, 1965; Langfitt et al., 1965; Zwetnow, 1970; Johnston et al., 1972, 1973). Extrapolation from the experimental to the clinical situation is also complicated by the use, in most laboratory studies, of a relatively rapid and progressive rise in intracranial pressure, which contrasts with the episodic and often infrequent rises seen clinically (Lundberg, 1960). Further, simultaneous recording of arterial and intracranial pressures during plateau waves in patients has shown that marked reductions in cerebral perfusion pressure may occur without any observable adverse effects, in apparent contradiction of most of the experimental results (Miller et al., 1972; Johnston and Paterson, 1974). Previous studies of cerebral blood flow changes during plateau waves have been entirely clinical, and have suggested that during such waves there is a fall in blood flow but an increase in cerebral blood

(Accepted 16 June 1975.) volume (Lundberg et al., 1968; Risberg et al., $\stackrel{\stackrel{\rho}{\oplus}}{\circ}$ 을 1969).

The aim of the present study was to examine experimentally the effects of episodic increases in intracranial pressure, simulating clinical plateaưo waves, on cerebral blood flow in primates. Metabolic studies were carried out simultaneously to determine whether changes in perfusion pressure adversely affected brain metabolism independent of changes in cerebral blood flow and also whether metabolic changes might trigger changes in cerebrovascular resistance, which would enable cerebral blood flow to be maintained despite very low perfusion pressures.

\section{METHODS}

Five baboons, weighing between 11 and $14 \mathrm{~kg}$, were anaesthetized using phencyclidine hydrochloride $(10 \mathrm{mg})$ and thiopentone sodium $(60 \mathrm{mg})$ for induction and phencyclidine hydrochloride, suxamethonium chloride, and nitrous oxide/oxygen for maintenance. Ventilation was controlled by means of a Starling pump delivering a tidal volume between 150 and $250 \mathrm{ml}$, adjusted according to arterial blood gas levels. Cannulae were placed in the following sites: 
1. Left femoral artery, for arterial pressure and intermittent blood gas and metabolite sampling.

2. Superior sagittal sinus, for continuous pressure recording and intermittent blood gas and metabolite sampling.

3. Cisterna magna, for continuous CSF pressure recording and infusion of 'mock' CSF to raise intracranial pressure.

4. Right lateral ventricle, for continuous intraventricular pressure recording.

5. Right lingual artery, for injection of ${ }^{133}$ Xenon for cerebral blood flow measurements.

Arterial, sagittal sinus, and intracranial pressures were measured using strain gauge pressure transducers (Bell \& Howell) and continuously recorded on paper chart recorders (Devices). Cerebral blood flow was estimated in two ways; (1) by the ${ }^{133}$ Xenon clearance method, using a slug injection of $0.5 \mathrm{mCi}$ ${ }^{133}$ Xenon dissolved in 0.45 to $0.55 \mathrm{ml}$ saline, into the lingual artery cannula (external carotid artery ligated); the rate of clearance of gamma activity was measured using a collimated 1.0 inch $(2.5 \mathrm{~cm})$ sodium iodide crystal detector placed over the right parietal region; blood flow was calculated from the initial slope and by the height over area method using a 10 minute correction; (2) by an electromagnetic flow probe (Nycotron) on the right common carotid artery (external carotid artery ligated).

End-tidal $\mathrm{CO}_{2}$ was continuously monitored using an infra-red analyser (Capnograph). Arterial and sagittal sinus $\mathrm{pH}, \mathrm{pO}_{2}$ and $\mathrm{pCO}_{2}$ levels, and arterial and sinus oxygen saturations were also measured at frequent intervals, as were arterial packed cell volume (PCV) and haemoglobin levels.

Blood for metabolic estimations was taken from the femoral artery and the superior sagittal sinus, the $2.5 \mathrm{ml}$ samples received into ice-cold perchloric acid and the acid extract treated as described by Johnson et al. (1969). Analyses were carried out for lactate and pyruvate (Hohorst et al., 1959), acetoacetate and 3-hydroxybutyrate (Williamson et al., 1962), glucose (Werner et al., 1970), and glycerol (Kreutz, 1962). Paired samples were taken during a control cerebral blood flow measurement and during the cerebral blood flow measurements which were carried out at the time of the first, third, and fifth pressure waves (vide infra). By reference to the corresponding cerebral blood flow measurements the cerebral uptake and output of metabolites were calculated.

The experimental design was as follows (Fig. 1):

1. Control conditions were established over 60 minutes.

2. Intracranial pressure was then increased rapidly to approximately $50 \mathrm{mmHg}$ by infusion of 'mock'

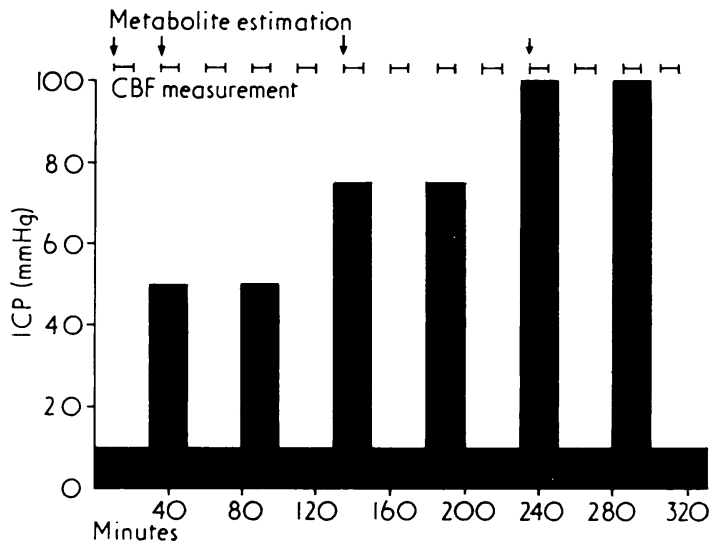

FIG. 1 Summary of experimental design - plateau' waies.

CSF into the cisterna magna and five minutes later cerebral blood flow and cerebral metabolite estimations were made. Intracranial pressure was maintained at $50 \mathrm{~mm} \mathrm{Hg}$ for 20 minutes and then allowed to fall rapidly.

3. Ten minutes after the end of the artificial pressure wave further measurements of cerebral blood flow were made.

4. Thirty minutes after the end of each pressure wave, a further such wave was induced and the same sequence of blood flow and metabolite measurements made. (Metabolite measurements were confined to the first, third, and fifth pressure waves, whereas blood flow and cerebral metabolic rate for oxygen $\left(\mathrm{CMRO}_{2}\right)$ were measured during each wave).

Each experiment consisted of six such waves, two at approximately $50 \mathrm{mmHg}$, two at approximately $75 \mathrm{mmHg}$, and two at approximately $100 \mathrm{mmHg}$.

\section{RESULTS}

1. INTRACRANiAl PRESSURES During the initial waves. intracranial pressure was easily maintained at the desired level for 20 minutes, and rapidly returned to control levels after infusion was discontinued. In the later stages of each experiment the pressure did not, however, always return to control levels, resulting in a variable degree of persistent intracranial hypertension.

2. CEREBRAL BLOOD FLOW Control values and values during and between successive pressure waves are shown in Tables la and b. During the 
TABLE 1

MEAN VALUES OF INTRACRANIAL PRESSURE (ICP), BLOOD PRESSURE (BP), SAGITTAL SINUS PRESSURE (SSP), CEREBRAL PERFUSION PRESSURE (CPP), CEREBROVASCULAR RESISTANCE (CVR), CEREBRAL BLOOD FLOW (CBF) AND CEREBRAL METABOLIC RATE, FOR OXYGEN $\left(\mathrm{CMRO}_{2}\right)$ IN FIVE ANIMALS: (a) DURING PRESSURE WAVES, AND $(b)$ BETWEEN PRESSURE WAVES

\begin{tabular}{|c|c|c|c|c|c|c|c|}
\hline & $\begin{array}{c}I C P \\
(m m H g)\end{array}$ & $\begin{array}{c}B P \\
(m m H g)\end{array}$ & $\begin{array}{c}S S P \\
(m m H g)\end{array}$ & $\begin{array}{c}C P P \\
(m m H g)\end{array}$ & $C V R$ & $\begin{array}{c}C B F \\
(\mathrm{ml} / 100 \mathrm{~g} / \mathrm{min})\end{array}$ & $\mathrm{CMRO}_{2}$ \\
\hline \multicolumn{8}{|c|}{ a. During pressure waves } \\
\hline $\begin{array}{l}\text { Control } \\
\text { Wave }\end{array}$ & 7 & 86 & 5 & 79 & 1.52 & 52 & 2.17 \\
\hline 1 & 48 & 104 & 16 & 56 & 1.19 & 47 & 2.15 \\
\hline 2 & 51 & 117 & 12 & 66 & 1.12 & 59 & 2.02 \\
\hline 3 & 71 & 126 & 26 & 55 & 0.98 & 56 & 2.27 \\
\hline 5 & 98 & 123 & 47 & 25 & 0.81 & 31 & 2.14 \\
\hline 6 & 98 & 117 & 40 & 19 & 0.83 & 23 & 2.10 \\
\hline \multicolumn{8}{|c|}{ b. Between pressure waves } \\
\hline $\begin{array}{l}\text { Control } \\
\text { Waves }\end{array}$ & 7 & 86 & 5 & 79 & 1.52 & 52 & 2.17 \\
\hline $1-2$ & 15 & 101 & 10 & 86 & 1.43 & 60 & 2.18 \\
\hline $2-3$ & 19 & 121 & 11 & 102 & 1.26 & 81 & 2.46 \\
\hline $3-4$ & 19 & 121 & 17 & 102 & 1.11 & 92 & 3.42 \\
\hline $5-6$ & 22 & 102 & 38 & 80 & 1.36 & 59 & 2.65 \\
\hline $6-7$ & 18 & 110 & - & 92 & 1.46 & 63 & - \\
\hline
\end{tabular}

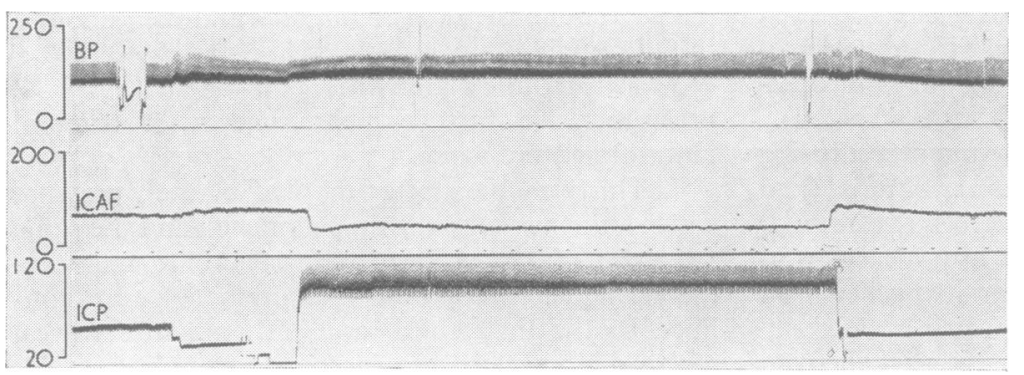

FIG. 2 Tracing showing marked reduction of hyperaemic internal carotid artery flow (ICAF) during pressure wave. (Absolute level of blood flow during waves was similar to initial control levels).

first four waves, blood flow remained relatively constant. Between pressure waves, however, a progressive hyperaemia developed, reaching a maximum between the third and fourth waves (an increase in mean cerebral blood flow of $76.9 \%$ ). Both the third and fourth pressure waves caused a marked reduction in cerebral blood flow from the hyperaemic values, but the actual flow levels fell only to approximately control values (Fig. 2). After the fourth, fifth, and sixth pressure waves, the hyperaemia was less marked, although cerebral blood flow still remained well above control levels. During the fifth and sixth waves, cerebral blood flow was reduced below control levels despite the persisting hyperaemia between waves. Nevertheless, moderate flows were still maintained, particularly in two of the five animals, despite marked reductions in cerebral perfusion pressure.

Among the five animals, there were some variations to this overall pattern. Thus, in one animal, which did not show a blood pressure response to the initial increase in intracranial pressure, cerebral blood flow fell during the first plateau wave.

Another animal developed a hyperaemia after the first plateau wave, and this increased during the second wave despite a fall in cerebral perfusion pressure.

3. BLOOD PRESSURE In general the animals showed an increase in blood pressure with in- 
creasing intracranial pressure (Tables $1 \mathrm{a}$ and $\mathrm{b}$ ), although the magnitude and timing of the response varied. Two animals showed a marked rise in blood pressure $(>40 \%$ control) with the initial increase in intracranial pressure, two showed a moderate rise, and one no rise, although this animal did show a marked increase in blood pressure with the second pressure wave. After the initial increase, the blood pressure remained higher than control levels at all times, although the pattern of response to subsequent waves differed. Three animals showed a further increase in blood pressure above the already increased basic level, with each successive wave. In the remaining two animals, the pattern was less clear: in one the blood pressure remained relatively constant after the initial rise and, in the other, the blood pressure fell during pressure waves and rose between them.

4. CEREBRAL PERFUSION PRESSURE (Mean blood pressure minus mean intracranial pressure) There was an initial fall in cerebral perfusion pressure during the first pressure waves. This was marked in three animals but relatively slight in two. After the first plateau wave, cerebral perfusion pressure remained above control levels, due to persistent systemic hypertension despite a return of intracranial pressure to control levels.

After the first and subsequent pressure waves, the mean value of cerebral perfusion pressure remained above the control mean, reaching a maximum of $102 \mathrm{mmHg}$ after the second and third waves. Each pressure wave caused a reduction in cerebral perfusion pressure, more marked with successive waves, until low values were reached during the final two waves (Tables 1a and $b$ ). Between the final three waves, there was also a fall in cerebral perfusion pressure, reflecting mainly the persistent increase in intracranial pressure referred to earlier.

5. SAGITTAL SINUS PRESSURE In all five animals, sagittal sinus pressure increased with increasing intracranial pressure (Tables $1 \mathrm{a}$ and $\mathrm{b}$ ) and, in four cases the increase was substantial. In the majority, the main rise in sagittal sinus pressure started during the third or fourth pressure wave, and, once an increase had occurred, the pressure tended to be higher during than between waves, although this was not invariably so. Mean values showed little difference during and between waves (Tables 1a and b). Rhythmic fluctuations in sagittal sinus pressure were also seen, and these were associated with simultaneous changes in intracranial pressure and internal carotid artery blood flow. Overall, no specific relationship was observed between sagittal sinus pressure and cerebral blood flow changes, and normal cerebral blood flow levels could be maintained despite persistently high sinus pressure between waves.

6. CEREBROVASCUlAR RESISTANCE Cerebrovascular resistance fell with the initial increase in intracranial pressure in each animal and continued to fall, to a progressively greater extent, during each subsequent wave. Between waves, cerebrovascular resistance tended to return towards control levels, although not reaching these values until the final stages of each experiment. During the hyperaemic phase, cerebro-

\section{TABLE 2}

MEAN AND STANDARD ERROR OF CONTROL LEVELS OF METABOLITES ASSAYED

\begin{tabular}{ll}
\hline Metabolites & Mean $S E$ \\
\hline Glucose $(\mathrm{mg} / 100 \mathrm{ml})$ & $116 \pm 9.3$ \\
Lactate $(\mu \mathrm{mol} / \mathrm{ml})$ & $1.19 \pm 0.23$ \\
Pyruvate $(\mu \mathrm{mol} / \mathrm{ml})$ & $0.096 \pm 0.032$ \\
Acetoacetate $(\mu \mathrm{mol} / \mathrm{ml})$ & $0.028 \pm 0$ \\
-OH butyrate $(\mu \mathrm{mol} / \mathrm{ml})$ & $0.068 \pm 0.01$ \\
Glycerol $(\mu \mathrm{mol} / \mathrm{ml})$ & $0.056 \pm 0.01$ \\
\hline
\end{tabular}

vascular resistance was lower than control levels, the maximum reduction coinciding with the period of marked hyperaemia.

7. CEREBRAL METABOLIC RATE FOR OXYGEN There was no change in mean $\mathrm{CMRO}_{2}$ during the initial pressure wave. With the development of a hyperaemia, however, $\mathrm{CMRO}_{2}$ increased progressively, being highest between waves and somewhat less during waves. The $\mathrm{CMRO}_{2}$ also remained high during the final waves when cerebral blood flow was falling.

\section{METABOLIC CHANGES Mean resting arterial}


TABLE 3

MEAN CHANGES IN UPTAKE OF METABOLITES DURING EPISODIC WAVES OF INCREASED INTRACRANIAL PRESSURE

\begin{tabular}{|c|c|c|c|c|c|}
\hline & $\begin{array}{c}\text { Glucose } \\
\text { (mg/100 } \mathrm{g} / \mathrm{min})\end{array}$ & $\begin{array}{c}\text { Pyruvate } \\
(\mu \mathrm{ml} / 100 \mathrm{~g} / \mathrm{min})\end{array}$ & $\begin{array}{c}\text { Lactate } \\
(\mu \mathrm{mol} / 100 \mathrm{~g} / \mathrm{min})\end{array}$ & $\begin{array}{c}\text { Acetoacetate } \\
(\mu \mathrm{mol} / 100 \mathrm{~g} / \mathrm{min})\end{array}$ & $\begin{array}{c}-O H \text { butyrate } \\
\text { (umol } 100 \mathrm{~g} / \mathrm{min})\end{array}$ \\
\hline $\begin{array}{l}\text { Pre-pressure wave } \\
\text { During pressure wave }\end{array}$ & $\begin{array}{l}+7.1 \\
+3.0\end{array}$ & $\begin{array}{l}+0.65 \\
+0.04\end{array}$ & $\begin{array}{l}-1.56 \\
-1.07\end{array}$ & $\begin{array}{l}+0.006 \\
-0.210\end{array}$ & $\begin{array}{l}+0.16 \\
-0.16\end{array}$ \\
\hline
\end{tabular}

levels of the metabolites assayed are shown in Table 2. An initial respiratory alkalosis was common (four animals) which reversed in three animals and progressed in the remaining animals. All animals showed changes in cerebral metabolism with raised intracranial pressure, but there was no consistent pattern. The most frequent change was either a reduction or reversal in the handling of ketone bodies by the brain, with raised intracranial pressure-that is, a change from uptake to output of ketones occurred in response to at least one period of raised intracranial pressure in each animal. On the other hand, reductions or reversals in handling of pyruvate or lactate were more variable. A reversal or $50 \%$ change in lactate metabolism occurred in nine out of 14 periods of raised intracranial pressure but, for pyruvate, in only five out of 14 . Uptake of glucose was largely unaffected by either raised intracranial pressure or arterial glucose levels, which rose substantially in three animals.

The mean transfer of metabolites before three rises in intracranial pressure in five animals and the mean transfer during waves of intracranial hypertension suggested, overall, that the latter caused an alteration and depression in cerebral metabolism, although none of the changes was statistically significant (Table 3).

\section{DISCUSSION}

The clinical observation that patients with intracranial hypertension may show severe reduction in cerebral perfusion pressure without any apparent adverse effects (Miller et al., 1972; Johnston and Paterson, 1974) is in contrast with experimental findings which would suggest that a progressive reduction of cerebral blood flow should accompany a falling cerebral perfusion pressure once this drops below a critical level
(Zwetnow, 1970). This apparent contradiction raises several important questions. First, does the absence of neurological dysfunction in patients with a seemingly inadequate cerebral perfusion pressure truly reflect relatively normal levels of cerebral blood flow? Second, if adequate cerebral blood flow is being maintained, what is the responsible mechanism, and third, is reversible or irreversible neurological damage resulting from the lowered cerebral perfusion pressure due either to alterations in blood flow or brain metabolism, which is not immediately reflected in the patient's clinical state?

The present experimental findings would sug. gest that relatively adequate cerebral blood flow levels are maintained during episodic increases in intracranial pressure with corresponding reductions in cerebral perfusion pressure. During the initial moderate increases in intracrania: pressure, hyperaemia developed which increased cerebral blood flow by approximately $100 \%$ during the periods between pressure waves. The hyperaemia was associated with both an increase in cerebral perfusion pressure and a reduction in cerebral vascular resistance but did not depend on any prior fall in either blood flow or perfusion pressure. Subsequent waves of intracranial pressure did reduce cerebral blood flow, but because of the high levels between waves, flow was maintained at relatively normal levels. Later in the experimental sequence, the hyperaemia between pressure waves diminished, and further pressure waves reduced cerebral blood flow below control levels, although relatively high flows were still maintained despite intracranial pressures exceeding $100 \mathrm{mmHg}$. The reduction in hyperaemia between waves was due largely to an increase in total vascular resistance, which may in part reflect increasing venous compression.

Does this mechanism operate in the clinical 
situation? A number of experimental studies have shown that hyperaemia will occur after the release of a sustained increase in intracranial pressure (Häggendal et al., 1970). Further, a period of hyperaemia may occur during sustained intracranial hypertension, but only when the increase in pressure is due to an increase in the CSF containing compartment and not due to a mass lesion (Johnston et al., 1972, 1973). Actual measurements of cerebral blood flow during plateau waves have shown that flow falls during the waves, although this fall may be accompanied by an increase in cerebral blood volume (Risberg et al., 1969), a discrepancy which the authors attributed to an increase in total vascular resistance, associated with venous compression. Correlation between the experimental findings and the clinical observations so far available is not therefore unequivocal and more clinical evidence is required before the experimental findings can be extrapolated to the clinical situation.

Turning to the mechanism of hyperaemia in general, there is as yet no satisfactory explanation. Both the magnitude and the time course of the increase in blood flow which may occur during or after a period of intracranial hypertension will depend inter alia on the nature of the increase in intracranial pressure (Zwetnow, 1970; Johnston et al., 1972, 1973). Why vascular dilatation does occur in these situations remains unknown, reflecting the basic ignorance of the mechanism of control of the calibre of the cerebral vessels-that is, the phenomenon of autoregulation (Green et al., 1963). The detailed studies of Zwetnow (1970) suggested that metabolic changes may be important, since hyperaemia was normally preceded by a substantial reduction in cerebral blood flow or cerebral perfusion pressure and, further, metabolic changes were demonstrated at intracranial pressure levels less than those needed to alter cerebral blood flow. In some of Zwetnow's experiments, however, as well as in other studies (EkstromJodal, 1972) and the present work, it was clear that a preceding fall in either blood flow or perfusion pressure was not a prerequisite for the development of hyperaemia. Further, there was no consistent metabolic change in the present study which might be held responsible.

The common coincidence of hyperaemia with a blood pressure response and also its occurrence in some instances with intracranial pressure changes alone certainly raises the possibility of a purely myogenic mechanism, based on changes in transmural pressure across the resistance vessels. It is worth noting that cerebral hyperaemia can also occur with spinal cord compression alone, when it is associated with a blood pressure response, good evidence against the primacy of underlying metabolic changes (Rowan and Johnston, 1975). These findings do not, however, rule out the possibility of a primary neurogenic action on the cerebral vessels, which have been shown to be richly innervated by adrenergic nerve fibres (Nelson and Rennels, 1970).

The intense sympathetic activity associated with the increase in intracranial pressure may thus be reflected in both systemic hypertension and intracranial vascular resistance changes. A complete understanding of the exact mechanism underlying the hyperaemia must, however, await a fuller understanding of the mechanism of auto-regulation in general, although, conversely, studies of hyperaemia may themselves shed some light on the unresolved questions concerning autoregulation.

The question whether such episodic increases in intracranial pressure do, in fact, cause reversible or irreversible damage to brain tissue, even in patients who remain clinically well, has as yet no clear-cut answer. There seems little doubt that metabolic changes in particular do occur, despite maintenance of adequate cerebral blood flow, although whether these result in permanent damage is uncertain. The answer to this critical question must await further studies of blood flow and metabolic changes in patients with plateau waves, as well as further attempts to reproduce the clinical situation in the laboratory.

In conclusion, it seems experimentally that episodic increases in intracranial pressure, simulating clinical plateau waves, cause cerebral hyperaemia, the onset of which does not depend on any consistent preceding changes in cerebral blood flow, cerebral perfusion pressure, or brain metabolism. Hyperaemia is characteristically associated with a blood pressure response, an increase in cerebral perfusion pressure and a fall in cerebral vascular resistance, and might result from intrinsic myogenic or neurogenic in- 
fluences on the cerebral vessels. Whatever the cause, development of hyperaemia may be the mechanism whereby cerebral blood flow is maintained in patients who show marked reduction in cerebral perfusion pressure during plateau waves. Both this and the question whether such patients actually suffer occult changes in brain blood flow and metabolism must, however, await further clinical studies.

The authors wish to thank Miss Christine McGregor, who carried out the biochemical estimations. Professor Bryan Jennett and Dr A. M. Harper contributed valuable advice and assistance throughout this study. Our thanks are also due to the technical staff of the Wellcome Surgical Research Institute.

\section{REFERENCES}

Ekstrom-Jodal, B. (1970). On the relation between blood pressure and blood flow in the canine brain with particular regard to the mechanism responsible for cerebral blood flow autoregulation. Acta Physiologica Scandinavica, suppl. 350.

Green, H. D., Rapela, C. E., and Conrad, M. C. (1963). Resistance (conductance) and capacitance phenomena in terminal vascular beds. In Handbook of Physiology, pp. 935-960. Edited by E. F. Hamilton and P. Dow. Section 2, Circulation, vol. 2. American Physiological Society: Washington.

Greenfield, J. C., and Tindall, G. T. (1965). Effect of acute increase in intracranial pressure on blood flow in the internal carotid artery of man. Journal of Clinical Investigation, 44, 1343-1351.

Häggendal, E., Lofgren, J., Nilsson, N. J., and Zwetnow, N. N. (1970). Effects of varied cerebrospinal fluid pressure on cerebral blood flow in dogs. Acta Physiologica Scandinavica, 79, 262-271.

Hohorst, H., Kreutz, F. H., and Bucher, T. (1959). Uber Metabolitgehaltz und Metabolit-konzentrationen in der Leber der Ratte. Biochemische Zeitschrift, 332, 18-46.

Johnson, R. H., Walton, J. L., Krebs, H. A., and Williamson, D. H. (1969). Metabolic fuels during and after severe exercise in athletes and non-athletes. Lancet, 2, 452-455.

Johnston, I. H., and Paterson, A. (1974). Benign intracranial hypertension. II CSF pressure and circulation. Brain, 97, 301-312.
Johnston, I. H., Rowan, J. O., Harper, A. M., and Jennett, W. B. (1972). Raised intracranial pressure and cerebral blood flow: 1. Cisterna magna infusion in primates. Journal of Neurology, Neurosurgery, and Psychiatry, 35, 285-296.

Johnston, I. H., Rowan, J. O., Harper, A. M., and Jennett, W. B. (1973). Raised intracranial pressure and cerebral blood flow: 2. Supratentorial and infratentorial mass lesions in primates. Journal of Neurology, Neurosurgery, and Psychiatry, 36, 161-170.

Kety, S. S., Shenkin, H. A., and Schmidt, C. F. (1948). The effects of increased intracranial pressure on cerebral circulatory functions in man. Journal of Clinical Investigation, 27, 493-499.

Kreutz, F. H. (1962). Enzymatic glycerin determination. Klinische Wochenschrift, 40, 362-363.

Langfitt, T. W., Kassell, N. F., and Weinstein, J. D. (1965). Cerebral blood flow with intracranial hypertension. Neurology (Minneap.), 15, 761-773.

Lundberg, N. (1960). Continuous recording and control of ventricular fluid pressure in neurosurgical practice. Acta Psychiatrica Scandinavica, 36, suppl. 149, 1-193.

Lundberg, N., Cronqvist, S., and Kjallqvist, A. (1968). Clinical investigation on interrelations between intracranial pressure and intracranial hemodynamics. Progress in Brain Research, 30, 69-75.

Miller, J. D., Stanek, A., and Langfitt, T. W. (1972). Concepts of cerebral perfusion pressure and vascular compression during intracranial hypertension. Progress in Brain Research, 35, 411-432.

Nelson, E., and Rennels, M. (1970). Innervation of intracranial arteries. Brain, 93, 475-490.

Risberg, J., Lundberg, N., and Ingvar, D. H. (1969). Regional cerebral blood volume during acute transient rises of intracranial pressure (plateau waves). Journal of Neurosurgery, 31, 303-310.

Rowan, J. O., and Johnston, I. H. (1975). Blood pressure response to raised CSF pressure. In Intracranial Pressure II, pp. 298-302. Edited by N. Lundberg, U. Ponten, and M. Brock. Springer: Berlin.

Werner, W., Rey, H. G., and Wielinger, H. (1970). Uber die Eigenschaften eines neuen Chromogens für die Blutzuckerbestimmung nach der GOD/POD-Methode. Zeitschrift für analytische Chemie, 252, 224-228.

Williamson, D. H., Mellanby, J., and Krebs, H. A. (1962). Enzymic determination of D-3-hydroxybutyrate and acetoacetic acid in blood. Biochemical Journal, 82, 90-96.

Zwetnow, N. N. (1970). Effects of increased cerebrospinal fluid pressure on the blood flow and on the energy metabolism of the brain. An experimental study. Acta Physiologica Scandinavica, suppl. 339. 